\section{Polyaniline Wires in Oxidant-Containing Mesoporous Channel Hosts}

\author{
Chun-Guey Wu and Thomas Bein* \\ Department of Chemistry, Purdue University \\ West-Lafayette, Indiana 47907 \\ Received February 4, 1994 \\ Revised Manuscript Received May 24, 1994
}

We report the encapsulation of polyaniline filaments in mesoporous hosts with $3 \mathrm{~nm}$ channel diameter. The channel size permits encapsulation of several polyaniline chains, and the resulting filaments show microwave conductivity. Processing of information at the molecular level is an intriguing and important challenge. Efforts to create electronic functions and devices based on molecules instead of bulk semiconductors are inspired by the anticipated enormous increase in computing speed and storage density. ${ }^{1,2}$ However, this approach requires that communication with nanometer structures or molecules can be established. A major challenge is to electrically isolate the conducting structures, and to achieve charge transfer with low fields as in metallic wires. We have recently demonstrated the encapsulation of several different conjugated polymers such as polypyrrole in the welldefined channels of zeolite molecular sieves. ${ }^{3}$ The synthesis of polyaniline in sol-gel-derived silica gel, ${ }^{4}$ and the template synthesis of conducting polymers in the pores (ca. $0.1-1 \mu \mathrm{m}$ ) of insulating host membranes has also been reported. ${ }^{5}$ Here we demonstrate the stabilization of conducting polyaniline filaments in the $3 \mathrm{~nm}$ wide hexagonal channels of transition-metal-containing mesoporous aluminosilicate host ${ }^{6} \mathrm{MCM}-41$.

Polyaniline is an unusual conducting polymer because its conductivity is not only controlled by the degree of chain oxidation but also by the level of protonation of $\left[(-\mathrm{BNHBNH}-)_{\mathrm{y}}(-\mathrm{BN}=\mathrm{Q}=\mathrm{N}-)_{1-y}\right]_{n}$, leading to the salt $\left\{(\mathrm{PhNH}-) \mathrm{A}_{x}\right\}_{n} \cdot{ }^{7,8}$ In the conducting salt form (emeraldine salt or PANI) $x$ and $y$ are close to $0.5 ; \mathrm{B}, \mathrm{Q}$, and $\mathrm{Ph}$ are $\mathrm{C}_{6} \mathrm{H}_{4}$ rings in the benzenoid, quinoid, and inter-

* Author for correspondence.

(1) (a) Carter, C. Molecular Electronic Devices; M. Dekker: New York, 1982. (b) Roth, S.; Mahler, G.; Shen, Y.; Coter, F. Synth. Met. 1989, 28, C815. (c) Aviram, A. J. Am. Chem. Soc. 1988, 110, 5687-92.

(2) Arrhenius, T. S.; Blanchard, D. M.; Dvolaitzky, M.; Lehn, J. M.; Malthete, J. Proc. Natl. Acad. Sci. U.S.A. 1986, 83, 5355-9.

(3) (a) Enzel, P.; Bein, T. J. Phys. Chem. 1989, 93, 6270. (b) Bein, T.; Enzel, P.; Beuneu, F.; Zuppiroli, L. in Electron Transfer Biol. Solid State 1990, 434. (c) Enzel, P.; Bein, T. J. Chem. Soc., Chem Commun. 1989, 1326. (d) Enzel, P.; Bein, T. Chem. Mater. 1992, 4, 819.

(4) Nishida, F.; et al. Mater. Res. Soc. Symp. Proc. 1990, 180 (Better Ceram. Chem. 4), 747-52.

(5) Martin, C. R.; Parthasarathy, R.; Menon, V. Synth. Met. 1993, 55, 1165-70 and references therein.

(6) (a) Beck, J.S.; Vartuli, J. C.; Roth, W. J.; Leonowicz, M. E.; Kresge, C. T.; Schmitt, K. D.; Chu, C. T.-W.; Olson, D. H.; Sheppard, E. W.; McCullenil, S. B.; Higgins, J. B.; Schlenker, J. L. J. Am. Chem. Soc. 1992, 114, 10834-10843. (b) Kresge, C. T.; Leonowicz, M. E.; Roth, W.; Vartuli, J. C.; Beck, J. S. Nature 1992, 359, 710-712. (c) Monnier, A.; Schuth, F.; Huo, Q.; Kumar, D.; Margolese, D.; Maxwell, R. S.; Stucky, G. D.; Krishnamurty, M.; Petroff, P.; Firouzi, A.; Janicke, M.; Chmelka, B. F. Science 1993, 261, 1299-1303.

(7) Huang, W.-S; Humphrey, B. D.; MacDiarmid, A. G. J. Chem. Soc., Faraday Trans. 1986, I82, 2385-2400.

(8) MacDiarmid, A. G.; Epstein, A. J. Faraday Discuss., Chem. Soc. $1989,88,317-332$. mediate states, respectively, and HA is a strong acid. A proton-induced spin unpairing process on imine nitrogens of the emeraldine salt form of polyaniline is believed to create a conducting polaron lattice. Clays and zeolites ion-exchanged with $\mathrm{Cu}^{2+}$ or $\mathrm{Fe}^{3+}$ have been shown to oxidatively polymerize various monomers of conjugated polymers such as anilines, ${ }^{9}$ pyrrole ${ }^{10}$ and thiophene and its derivatives ${ }^{3 c, 11}$ inside their cavities. The in situ oxidative polymerization/intercalation of conducting polymers in layered materials containing strong oxidants has also been demonstrated. ${ }^{12}$

Here we have carried out in situ oxidative adsorption/ polymerization of aniline vapor in $\mathrm{Cu}-\mathrm{MCM}$ (or $\mathrm{Fe}-$ MCM), either in the absence or presence of air (details in Table 1). The encapsulated emeraldine salt was formed by first adsorbing aniline vapor into the host; 13 a maximum of $0.3 \mathrm{~g}$ of aniline adsorbed in $1.0 \mathrm{~g}$ of $\mathrm{Cu}-\mathrm{MCM}$ or $\mathrm{Fe}-$ MCM (Table 1). Under exclusion of air, the saturated pink adduct (AN-CuMCM-0, AN-FeMCM-0) was then immersed in an acidic aqueous solution of peroxydisulfate, and a drastic color change to dark green was observed. After thorough washing with water, the materials were dried under vacuum. A typical polymer loading is 0.16 $\mathrm{g} / 1.00 \mathrm{~g}$ of $\mathrm{Cu}-\mathrm{MCM}$ host. The following will address the nature of the encapsulated material, its location, and its ac conductivity.

The $\mathrm{Cu}$ or Fe ion content in MCM-41 is low due to the low negative charge on the framework $(\mathrm{Si} / \mathrm{Al}=18)$ and incomplete ion exchange ( $\mathrm{Cu} / \mathrm{Al}$ ratio equal to 0.21 ). Therefore there may not be sufficient oxidant to polymerize large amounts of polyaniline inside the host. By carrying out the reaction in air, oxygen could be an indirect oxidant which continues to oxidize the $\mathrm{Cu}^{+}\left(\mathrm{Fe}^{2+}\right)$ to $\mathrm{Cu}^{2+}$ $\left(\mathrm{Fe}^{3+}\right)$ during the reaction. This effect has been observed in other cases. ${ }^{14}$ However, when the reaction was carried out in air, the resulting product AN-FeMCM-2 is not emeraldine salt ES (nor emeraldine base which shows a strong IR peak at $1594 \mathrm{~cm}^{-1}$ ), but predominantly the nonconducting leucoemeraldine LEB, as demonstrated with IR and NMR spectroscopy (major IR peaks at 1558 sh, $1497 \mathrm{vs}$, and $\left.1296 \mathrm{~m} \mathrm{~cm}^{-1}\right) .{ }^{15}$ The ${ }^{13} \mathrm{C}$ MAS NMR spectra of conducting polyaniline are featureless due to the presence of charges, which together with the inhomogeneous character of the materials, results in broadened

(9) Mehrotra, V.; Giannelis, E. P. Mater. Res. Soc. Symp. Proc. 1990 , $171,39-44$.

(10) Bein, T.; Enzel, P. Angew. Chem., Int. Ed. Engl. 1989, 28, 1692.

(11) (a) Soma, Y.; Soma, M.; Furukawa, Y.; Harada, I. Clays Clay Miner. 1987, 35, 53-59. (b) Hwang, B.; Chon, H. Zeolites 1990, 10, 101104.

(12) (a) Kanatzidis, M. G; Tonge, C. R.; Mercy, H. O.; Marks, T. J.; Kannewurf, C. R.J.Am. Chem.Soc. 1987, 109, 3797-3799. (b) Kanatzidis, M. G.; Wu, C.-G.; Marcy, H. O.; Kannewurf, C. R. J. Am. Chem. Soc. 1989, 111, 4139-4141. (c) Wu, C.-G.; Marcy, H. O.; DeGroot, D. C.; Kannewurf, C. R.; Schindler, J. L.; Leang, W. Y.; Benz, M.; LeGoff, E.; Kanatzidis, M. G. Synth. Met. 1991, 41/43, 797-803.

(13) The host was synthesized with $\mathrm{C}_{16} \mathrm{H}_{33} \mathrm{~N}\left(\mathrm{CH}_{3}\right)_{3} \mathrm{OH}$ according to ref $6 ; \mathrm{Si} / \mathrm{Al}$ ratio of 18 , calcined at $580^{\circ} \mathrm{C}$ and evacuated at $400^{\circ} \mathrm{C}, 10^{-5}$ Torr. To load with copper ions, $1.00 \mathrm{~g}$ of the calcined MCM was stirred for $3 \mathrm{~h}$ at $25^{\circ} \mathrm{C}$ with $100 \mathrm{~mL}$ of $0.1 \mathrm{M} \mathrm{Cu}$ (II) nitrate (aq), filtered, washed with water. These steps were repeated four times. To load with $\mathrm{Fe}, 1.00$ $\mathrm{g}$ of MCM was stirred with $100 \mathrm{~mL}$ of $0.1 \mathrm{M} \mathrm{Fe}$ (II) nitrate (aq) under nitrogen for $4 \mathrm{~h}$, filtered, and washed with water. The product was treated in an oxygen flow at $100^{\circ} \mathrm{C}$ for $10 \mathrm{~h}$, at $350^{\circ} \mathrm{C}$ for $4 \mathrm{~h}$, and evacuated at $350^{\circ} \mathrm{C}$ for $2 \mathrm{~h}$. Slight decreases in crystallinity were observed. Before loading with aniline, the $\mathrm{Cu}-$ and $\mathrm{Fe}-\mathrm{MCM}$ hosts were heated at $100^{\circ} \mathrm{C}$ and $400^{\circ} \mathrm{C}$ in oxygen, then evacuated at $400^{\circ} \mathrm{C}$ for $7 \mathrm{~h}$

(14) Wu, C.-G. Ph.D. Dissertation Michigan State University, 1992.

(15) (a) Harada, I; Furukawa, Y; Ueda, F. Synth. Met. 1989, 29, E303312. (b) Cao, Y. Synth. Met. 1990, 35, 319-332. 
Table 1. Polyaniline in CuMCM and FeMCM Hosts

\begin{tabular}{|c|c|c|c|c|}
\hline sample & reaction sequence $^{c}$ & loading $^{b}(\mathrm{wt} \%$ ) & product ${ }^{c}$ & ac conductivity $(\mathrm{S} / \mathrm{cm})$ \\
\hline $\begin{array}{l}\text { AN-CuMCM-0 } 0^{d} \\
\text { AN-CuMCM-1 } \\
\text { AN-CuMCM-2 } \\
\text { AN-FeMCM-1 }{ }^{d} \\
\text { AN-FeMCM-2 } \\
\text { dry CuMCM } \\
\text { bulk polyaniline (as prepared) }\end{array}$ & $\begin{array}{l}\text { vapor } \\
\text { A: vapor } / \mathrm{S}_{2} \mathrm{O}_{8}{ }^{2-} \\
\mathrm{B}: \text { vapor } / \text { air } / \mathrm{S}_{2} \mathrm{O}_{8}{ }^{2-} \\
\text { A: vapor } / \mathrm{S}_{2} \mathrm{O}_{8}{ }^{2-} \\
\text { C: vapor in air }\end{array}$ & $\begin{array}{r}28 \\
10 \\
20 \\
6 \\
10 \\
0\end{array}$ & $\begin{array}{l}\text { radicals/cations } \\
\text { ES } \\
\text { ES and others } \\
\text { ES } \\
\text { LEB } \\
\text { E- } \\
\text { ES }\end{array}$ & $\begin{array}{l}3.6 \times 10^{-4} \\
1.6 \times 10^{-3} \\
1.6 \times 10^{-3} \\
9.4 \times 10^{-5} \\
9.4 \times 10^{-5} \\
1.8 \times 10^{-2}\end{array}$ \\
\hline
\end{tabular}

- Sequence A: dry CuMCM host was equilibrated with aniline vapor at $40^{\circ} \mathrm{C}$ for $4 \mathrm{~h}$, then pumped off for 10 min, and immersed in an aqueous solution of peroxydisulfate under nitrogen at $0^{\circ} \mathrm{C}$ for $4 \mathrm{~h}$ (mole ratio of oxidant vs aniline $1.25: 1,1 \mathrm{~g}$ of sample in $50 \mathrm{~mL}$ of $0.2 \mathrm{M} \mathrm{HCl}$ ). Sequence $\mathrm{B}$ : dry CuMCM host was equilibrated with aniline vapor at $25^{\circ} \mathrm{C}$ for $24 \mathrm{~h}$, then pumped off for 10 min, exposed to air, and then immersed in an aqueous solution of peroxydisulfate at $0^{\circ} \mathrm{C}$ for $4 \mathrm{~h}$ (mole ratio of oxidant vs aniline 1.25:1, $\mathrm{g}$ of sample in $50 \mathrm{~mL}$ of $0.2 \mathrm{M} \mathrm{HCl}$ ). Sequence C: dry CuMCM host was equilibrated with aniline vapor at $40^{\circ} \mathrm{C}$ for $4 \mathrm{~h}$ in the presence of air and then pumped off for $1 \mathrm{~h}$. ${ }^{b}$ Determined from TGA weight loss between 100 and $600^{\circ} \mathrm{C} .{ }^{c}$ ES: emeraldine salt; LEB: leucoemeraldine base. ${ }^{d}$ All MCM samples indicated were pumped at $10^{-5}$ Torr for $12 \mathrm{~h}$ at room temperature.

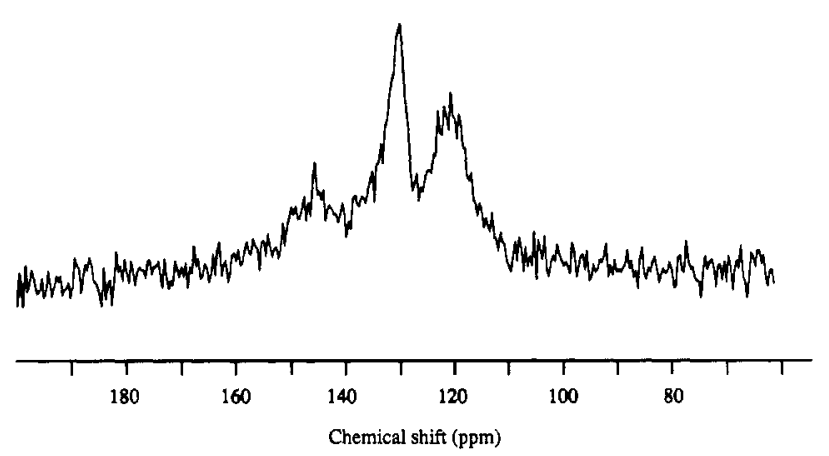

Figure 1. MAS ${ }^{13} \mathrm{C}$ NMR of sample AN-FeMCM-2.

peaks. ${ }^{16}$ The reduced form of polyaniline (leucoemeraldine) has the simplest structure among all modifications of polyaniline. There are only two different types of carbon in the structure. The ${ }^{13} \mathrm{C}$ NMR of AN-FeMCM-2 shows two peaks at about 130 and $120 \mathrm{ppm}$, typical for leucoemeraldine (Figure 1). ${ }^{16}$ The same experiment with $\mathrm{Cu}-$ MCM host results in a dark brown material which contains a mixture of products.

As expected, when the exposure to aniline vapor was carried out under vacuum, no polymer was formed (sample $\mathrm{AN}-\mathrm{Cu}-\mathrm{MCM}-0$ ). The pink products may contain some radicals and cations of aniline or its oligomers, as indicated by an electronic absorption peak at $410 \mathrm{~nm}$. This peak is consistent with the presence of nitrenium cations $\left(\mathrm{C}_{6} \mathrm{H}_{5}\right.$ $\left.\mathrm{NH}^{+}\right)$or nitrenium radicals $\left(\mathrm{C}_{6} \mathrm{H}_{5} \mathrm{NH}^{\bullet}\right){ }^{17,18}$ The cations and radicals are quite reactive; upon contact with air, the color turns brown and only a fraction of the resulting products can be further polymerized with $\left(\mathrm{NH}_{4}\right)_{2} \mathrm{~S}_{2} \mathrm{O}_{8} /$ $\mathrm{HCl}$ to form polyaniline (sample $\mathrm{AN}-\mathrm{Cu}-\mathrm{MCM}-2$ ). However, if the pink materials are reacted with $\left(\mathrm{NH}_{4}\right)_{2} \mathrm{~S}_{2} \mathrm{O}_{8} /$ $\mathrm{HCl}$ aqueous solution before exposure to air, the resulting dark green products, AN-CuMCM-1 and AN-FeMCM-1, both contain the emeraldine salt form as shown in Scheme 1 and Figure 2 (IR peaks at 1581, 1497, 1300, and 1230 $\left.\mathrm{cm}^{-1}\right) .{ }^{19}$ The electronic absorption spectrum of $\mathrm{AN}-$ CuMCM-1 and AN-FeMCM-1 presents major transitions at 3.4 and $1.6 \mathrm{eV}$, typical for the bandgap and polaron transitions of emeraldine salt. ${ }^{18,20}$ The encapsulated, evacuated polymers show a single fairly broad (8-19 G)

(16) (a) Kaplan, S.; Conwell, E. M.; Richter, A. F.; MacDiarmid, A G. J.Am. Chem. Soc. 1988, 110,7647-7651. (b) Menardo, C.; Nechtschein M.; Rousseau, A.; Travers, J. P.; Hany, P. Synth. Met. 1988, 25, 311-322.

(17) Lapkowski, M. Synth. Met. 1990, 35, 169-182

(18) (a) Mohliner, D. M.; Adams, R. N.; Argersinger, W. J. J. Am. Chem. Soc. 1962, 84, 3618. (b) Diaz, A. F.; Logan, J. A. J. Electroanal. Chem. 1980, 111, 111 .

(19) Furukawa, Y.; Ueda, F.; Hyodo, Y.; Harada, I.; Nakajima, T.; Kawagoe, T. Macromolecules 1988, 21, 1297-1305.

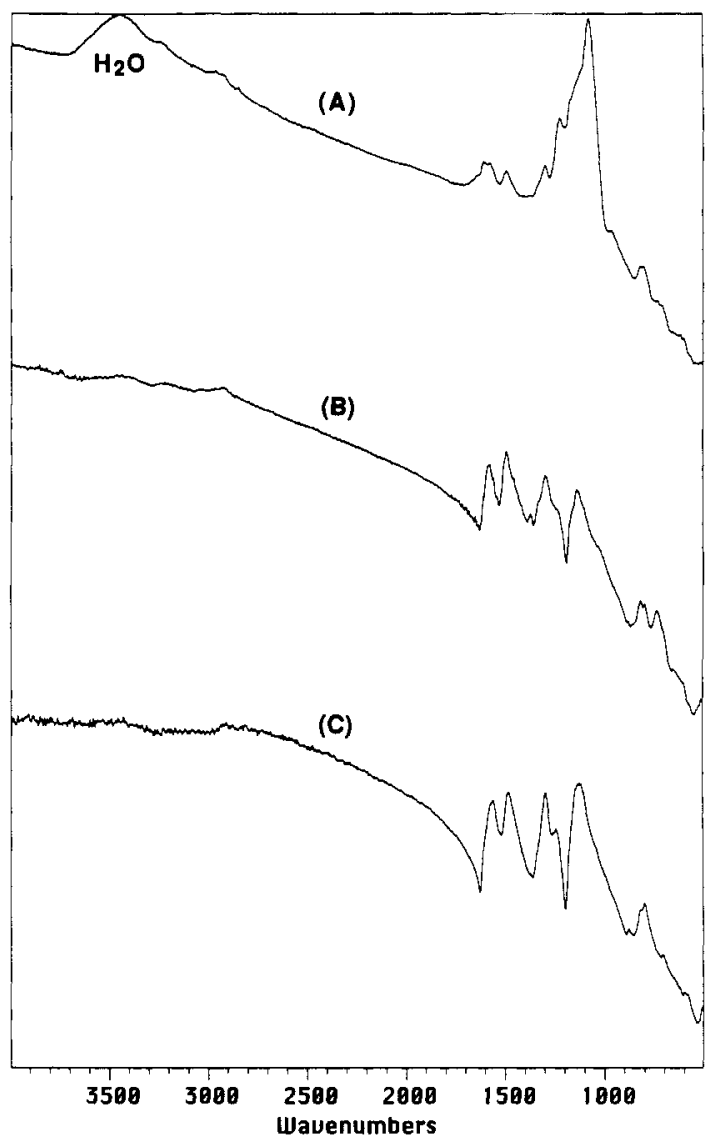

Figure 2. Infrared spectra of (A) AN-CuMCM-1, (B) PANI extracted from the composite in (A), and (C) bulk PANI.

esr line for the polymer (and a weak $\mathrm{Cu}$ (II) resonance), as presented in Figure 3, suggesting slightly lower protonation levels than in bulk emeraldine salt ${ }^{21}$ or dipolar interactions with the MCM channel walls or metal cations inside.

The relative chain length of intrachannel polyaniline in AN-FeMCM-1 (vs polystyrene, in $N$-methylpyrrolidinone with $2.5 \% \mathrm{LiCl}$ ) was determined with gel permeation chromatography after decomposition of the host in 5\% HF and deprotonation. (Polyaniline is stable toward HF under these conditions; IR spectra and conductivity are unchanged). A correction factor of ca. 0.5 is required to estimate absolute molecular weights. ${ }^{22}$ The peak mo-

(20) Shacklette, L. W.; Wolf, J. F.; Gould, S.; Baughman, R. H. J. Chem. Phys. 1988, 88, 3955-3961.

(21) Javadi, H. H. S.; Laversanne, R.; Epstein, A. J.; Kohli, R. K.; Scherr, E. M.; MacDiarmid, A. G. Synth. Met. 1989, 29, E439-E444.

(22) Oh, E. J.; et al. Synth. Met. 1993, 55, 977-82. 


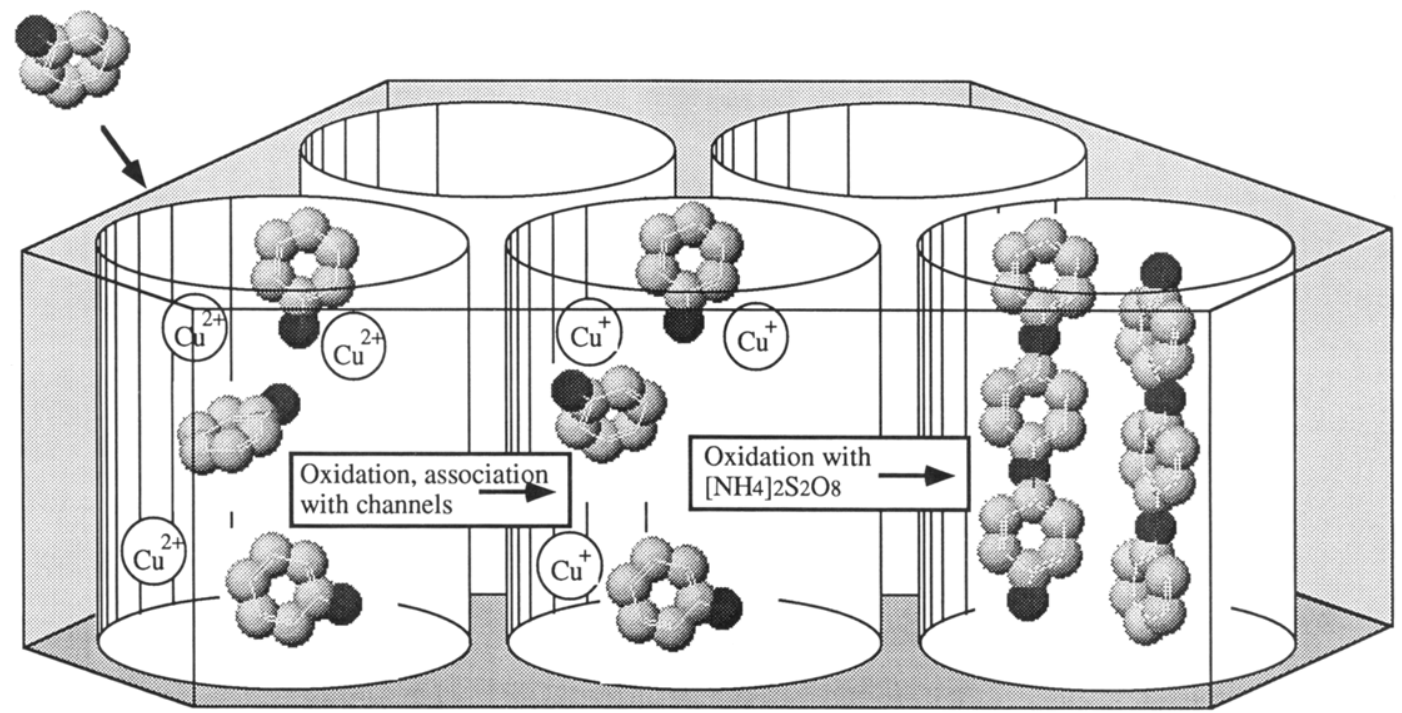

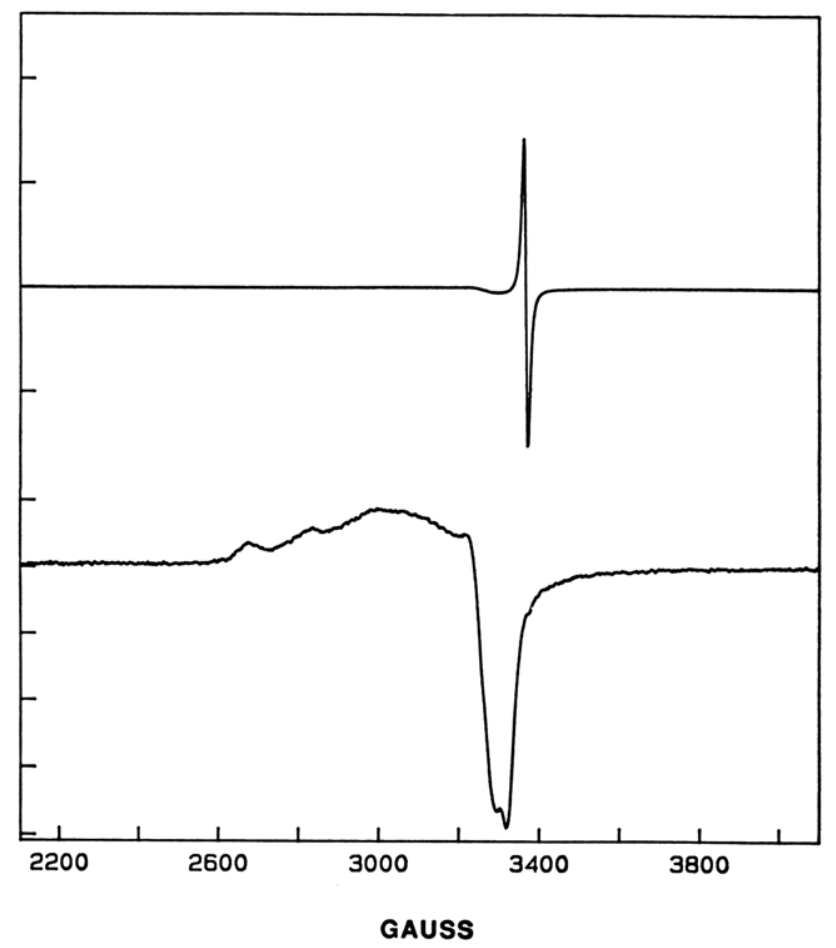

Figure 3. ESR spectra of (top) sample AN-CuMCM-2 and (bottom) CuMCM (scale different from top).

lecular weight of the intrachannel polyaniline (34 $000 \mathrm{vs}$ PS; corrected ca. 190 rings) is consistently shorter than that of bulk material synthesized under comparable conditions (52 000 vs PS; corrected ca. 290 rings). This difference suggests that diffusional constraints experienced by the reactants limit the chain growth in the MCM host.

TGA experiments in oxygen show that the stability of AN-CuMCM-1 and AN-FeMCM-1 is much higher (decomposition between 350 and $600^{\circ} \mathrm{C}$ ) than that of bulk ES (decomposition between 300 and $400{ }^{\circ} \mathrm{C}$ ). This difference indicates slower diffusion of oxygen and reaction products, similar to observations for polymers in layered hosts. ${ }^{23}$ With the sample AN-CuMCM-0 where little polymer forms, most of the weight loss occurs at temperatures below $200^{\circ} \mathrm{C}$.

(23) Kato, C.; Kuroda, K.; Misawa, H. Clays Clay Miner. 1979, 27, 129. (b) Blumstein, A. J. Polym. Sci., Part A 1965, 3, 2665.
The location of the polymer (inside vs outside of the channels) is important for the interpretation of the results. Infrared spectra of the hydroxyl region of $\mathrm{Cu}-\mathrm{MCM}-41$ before aniline loading show a single peak at $3691 \mathrm{~cm}^{-1}$ (in Nujol), due to $\mathrm{Si}-\mathrm{OH}$, which disappears on contact with aniline. This indicates complete coverage of the intrachannel surface with aniline. The intrachannel polymerization reaction was probed with nitrogen sorption. The isotherm of $\mathrm{AN}-\mathrm{CuMCM}-1$ shows a residual pore volume of $0.43 \mathrm{~mL} / \mathrm{g}$ of MCM host (it contains $0.16 \mathrm{~g}$ of polymer $/ \mathrm{g}$ of $\mathrm{Cu}-\mathrm{MCM}$ ), compared with $0.64 \mathrm{~mL}$ pore volume in the empty host. Assuming a polymer density of $1.3 \mathrm{~g} / \mathrm{cm}^{3}$, the loading of $0.16 \mathrm{~g} /(\mathrm{g}$ of host) is slightly smaller than the change in porosity probed with nitrogen sorption, possibly indicating blockage of some channels. However, the general similarity of the unique isotherm shapes suggests that a tubular structure is even maintained in the polyaniline-loaded host, but the shift of the saturation transition to lower partial pressure shows that the channels are now narrowed.

The electronic conductivity of the encapsulated polyaniline is of primary interest. Detailed studies of bulk emeraldine salt led to the model of a granular metal where charge hopping between metallic bundles dominates the macroscopic conductivity. ${ }^{24,25}$ The de conductivity of ANCuMCM-1 and AN-FeMCM-1 is in the $10^{-8} \mathrm{~S} / \mathrm{cm}$ range, similar to the conductivity of unloaded $\mathrm{Cu}-\mathrm{MCM}$ host under ambient conditions, and more than 7 orders of magnitude lower than for bulk PANI. This shows that the polyaniline is located inside the MCM channels and that no percolating conducting paths develop on the external crystal surfaces.

To probe the charge transport of PANI filaments in the insulating MCM host, the contactless microwave absorption technique ${ }^{26}$ was used. The microwave conductivity of dry AN-CuMCM-1 and AN-FeMCM-1 obtained from the perturbation of a rectangular cavity at $2.63 \mathrm{GHz}$ is no less than about one-tenth of that of as-synthesized bulk $P A N I$ (with dc conductivity of $0.2 \mathrm{~S} / \mathrm{cm}$ ), after correction

(24) Wang, Z. H.; Scherr, E. M.; MacDiarmid, A. G.; Epstein, A. J. Phys. Rev. 1992, B45, 4190-202.

(25) Javadi, H. H. S.; Cromack, K. R.; MacDiarmid, A. G.; Epstein, A. J. Phys. Rev. B 1989, 39, 3579-3584.

(26) Dube, D. C.; Lanagan, M. T.; Kim, J. H.; Jang, S. J. J. Appl. Phys. 1988, 63, 2466-68. 
for the volume fraction of the polymer in the host (Table 1). ${ }^{27}$ This significant low-field conductivity demonstrates that conjugated polymers can be encapsulated in nanometer channels and still support mobile charge carriers (in contrast to polypyrrole in the $0.7 \mathrm{~nm}$ channels of zeolite $\mathrm{Y}$ that is not conducting). ${ }^{28}$ Moreover, the ac conductivity of AN-CuMCM-1 is similar to that of PANI in pristine MCM. ${ }^{29}$ This indicates that the presence of oxidant ions does not significantly affect the charge-transport proper-

(27) The ac conductivity calculated for the dry empty CuMCM host is only $1 / 100$ th of the PANI-filled host.

(28) Zuppiroli, L.; Beuneu, F.; Mory, J.; Enzel, P.; Bein, T. Synth. Met. 1993, 55-57, 5081-5087.

(29) Wu, C.-G.; Bein, T. Science 1994, 264, 1757-1759. ties of the polyaniline chains in the host. The concept of in situ oxidative adsorption/polymerization of aniline in the oxidant-containing channel host permits us to "lock in" the aniline species as radical cations or short oligomers such that diffusion during subsequent treatment with external oxidant is limited. The factors controlling electronic transport in these and related novel nanostructures are now being studied.

Acknowledgment. The authors are grateful for partial funding from Sprague Electric Company. The contribution of Stephane Esnouf to the microwave conductivity measurements is greatly appreciated. 